УДК 664.005.6

DOI 10.29141/2500-1922-2021-6-1-1

\title{
«Дерево свойств»
}

\section{в оценке потребительских критериев сахаристых кондитерских изделий}

\author{
И.Ю. Резниченко ${ }^{1 *}$, Н.А. Фролова ${ }^{2}$, Е.Е. Жарская ${ }^{1}$, Я.С. Ковальчук ${ }^{1}$, М.А. Соловьева \\ ${ }^{1}$ Кемеровский государственный университет, г. Кемерово, Российская Федерация, *e-mail: irina.reznichenko@gmail.com \\ ${ }^{2}$ Амурский государственный университет, г. Благовещенск, Российская Федерация
}

Ключевые слова:

карамельные

изделия;

критерии;

иерархическая

структура;

сенсорные

характеристики;

качество

\begin{abstract}
Реферат
В статье представлены результаты анализа развития потребительского рынка сахаристых кондитерских изделий на современном этапе. Проанализирован рынок карамели в России за период 2019-2020 гг. Отмечено, что производство карамели характеризуется нестабильностью. В 2019 г. объемы производства карамели на 2,8 \% были ниже по сравнению с 2018 г., а в 2020 г уменьшились еще на 12,2 \% к уровню 2019 г. Зафиксировано изменение структуры рынка: сокращается сегмент традиционной карамели, возрастает сегмент функциональной. Предложено «дерево свойств» для оценки потребительских критериев сахаристых кондитерских изделий на примере карамели с начинкой, для чего проведены анализ потребительских критериев (факторов, сохраняющих качество (упаковки, маркировки); показателей назначения, экологических и эргономических), а также исследование органолептических, физико-химических показателей. Иерархическая структура «дерева свойств» отражает номенклатуру показателей, в том числе не регламентированных требованиями нормативных документов. Приведены результаты исследований показателей качества шести образцов карамели с начинкой, реализуемых федеральным ритейлом. Выявлены соответствия и несоответствия требованиям действующих нормативных документов. Определено, что из показателей социального назначения ключевым для потребителя является доступная цена, при этом изделие должно обладать соответствующими сенсорными характеристиками и не иметь в составе синтетических ароматизаторов и красителей. Эстетические показатели отражают доступную и достоверную информацию о продукте, вид упаковочного материала и красочность оформления, а также влияние утилизации упаковки на окружающую среду. Полученные результаты могут быть полезны производителям и практикующим работникам торговли при формировании ассортимента продукции торговой организации.
\end{abstract}

\section{"Properties Tree" in the Consumer Criteria Evaluation for Sugary Confectionery Products} \section{Irina Yu. Reznichenko ${ }^{1 *}$, Nina A. Frolova ${ }^{2}$, Ekaterina E. Zharskaya', Yana S. Kovalchuk ${ }^{1}$,} Margarita A. Solovyova ${ }^{1}$

${ }^{1}$ Kemerovo State University, Kemerovo, Russian Federation, *e-mail: irina.reznichenko@gmail.com ${ }^{2}$ Amur State University, Blagoveshchensk, Russian Federation

Keywords: caramel products; criteria;

\section{Abstract}

The article concerns the development analysis results of the consumer market of sugar confectionery products at the present stage. The authors analyzed caramel market in 
hierarchical structure; sensory characteristics; quality
Russia for the period 2019-2020. They note that the caramel production is not stable. In 2019 , the volume of caramel production was $2.8 \%$ lower compared to 2018, and in 2020 it decreased by another $12.2 \%$ compared to 2019 . The researchers recorded the change in the market structure: the traditional caramel segment was shrinking; the functional segment was increasing. They revealed "property tree" for evaluating consumer criteria of the sugar confectionery on the example of caramel with filling; to do this they conducted the consumer criteria analysis (factors preserving the quality (packaging, labelling); destination indicators; ecological and ergonomic indexes), and a study of organoleptic, physical and chemical parameters. The hierarchical structure of the "property tree" reflects the indicators nomenclature, including those that are not regulated by the requirements of regulatory documents. The thesis presented quality indicators studies result of six samples of caramel with filling sold by the federal retail. The authors identified the compliance and non-compliance with the requirements of the current regulatory documents. They determined that among the indicators of social purpose, the key for the consumer was an affordable price, while the product had to contain the appropriate sensory characteristics and had to exclude synthetic flavors and dyes. Aesthetic indicators reflect the available and reliable information about the product, the type of packaging material and colorfulness of the design, as well as the impact of packaging disposal on the environment. The results obtained can be useful for manufacturers and practitioners of trade in the formation of the product range of a trade organization.

For citation: Irina Yu. Reznichenko, Nina A. Frolova, Ekaterina E. Zharskaya, Yana S. Kovalchuk, Margarita A. Solovyova. Properties Tree in the Consumer Criteria Evaluation for Sugary Confectionery Products. Индустрия numaнuя/Food Industry. 2021. Vol. 6, No. 1. Pp. 5-12. DOI: 10.29141/2500-1922-2021-6-1-1

Paper submitted: December 20, 2020

\section{Введение}

В настоящее время потребительский рынок сахаристых кондитерских изделий характеризуется насыщенностью ассортимента и разнообразием видов.

Среди всех сахаристых кондитерских изделий доступностью ценовой категории выделяется карамель. Карамель, как леденцовая, так и с начинками, остается популярным и востребованным продуктом, особенно на фоне снижения доходов населения, вызванного нестабильностью экономического климата, в том числе из-за коронавируса. Отмечаются низкий потребительский спрос населения и режим жесткой экономии, о6условленные ростом безработицы и желанием создать финансовую подушку «на черный день» (повторная вспышка пандемии) ${ }^{1}$. Понижение доходов граждан России более чем на 4 \% привело к постепенному переходу на сберегающую модель потребления, к оптимизации расходов, отказу от дорогих кондитерских изделий и выбору более доступной кондитерской продукции ${ }^{2}$.

\footnotetext{
'Влияние COVID-19 на экономику. Аналитические материалы COFACE. URL: http://www.coface.ru/Novosti-i-Publikacii/ Publikacii/Vliyanie-COVID-19-na-ekonomiku.-Analiticheskiematerialy-Coface.

2 Рынок сахаристых кондитерских изделий в РФ. URL: https://www.indexbox.ru/news/po-itogam-dvukh-mesyatsev2016-goda-proizvodstvo-karameli-snizilos/.
}

Анализ рынка карамели в Российской Федерации за период 2019-2020 гг. показал, что производство карамели характеризуется нестабильностью. Так, в 2019 г. объемы производства карамели на 2,8 \% были ниже чем в 2018 г., а в 2020 г. уменьшились еще на 12,2 \% к уровню 2019 г. Лидером по производству карамели признан Центральный федеральный округ с долей $65 \%$ от общего произведенного объема 3 . В 2020 г. цена на карамель уменьшилась в среднем на $0,8 \%$, составив около 215 р./k $\Gamma^{3,4}$.

С развитием рынка поменялась его структура: сокращается сегмент традиционной карамели, расширяется сегмент функциональных изделий (с экстрактами растительного сырья, обогащенной, специализированного назначения) [1-5]. Это согласуется с ростом потребительского спроса на продукцию витаминизированную, функциональную, т. е. на продукты здорового питания [6-10]. Однако для потребителей, наряду с полезностью, важными являются качественные характеристики, которые выражаются восприимчивостью сенсорных свойств.

\footnotetext{
${ }^{3}$ Рынок карамели в России. Текущая ситуация и прогноз на 2020-2024 гг. URL: https://alto-group.ru/otchot/rossija/265rynok-karameli-v-rossii-tekuschaja-situacija-i-prognoz-20202024-gg.html.

${ }^{4}$ Российский рынок карамели: комплексный анализ и прогноз. URL: https://marketing.rbc.ru/research/34415/.
} 
Разработкой концепции воспринимаемости сенсорного качества потребителями (PSQ) занимаются многие ученые, и вызвано это тем, что именно органолептические характеристики играют ведущую роль при выборе продукта. Отмечено, что потребительское восприятие субъективно и непостоянно, но исследования меняющихся потребительских требований и выпуск продукции, отвечающей спросу покупателей, остаются актуальным научным направлением [4; 7; 11]. Инструменты управления качеством зарекомендовали себя как эффективные для выявления потребительских требований, повышения конкурентоспособности продукции, поиска новых критериев качества.

Производители решают задачу - преобразовать критерии «потребительского ожидания» в точно измеряемые научные параметры, поэтому необходимо знать все показатели качества, которые важны для потребителя [12].

Новизна проведенных исследований заключается в оценке качества сахаристых кондитерских изделий с учетом потребительских критериев выбора и в получении данных, которые могут быть полезными производителям и работникам торговли при формировании ассортимента кондитерской продукции.

Все вышеизложенное послужило основой для постановки цели работы - на основе предложенного авторами «дерева свойств» исследовать потребительские критерии карамели с начинкой, выявить соответствие показателей качества требованиям нормативной документации и ожиданиям потребителей.

В задачи исследования входило:

- построение «дерева свойств»;

- анализ потребительских критериев: факторов, сохраняющих качество (упаковка, маркировка); показателей назначения - экологических и эргономических;

- анализ органолептических, физико-химических показателей продукта.

\section{0бъекты и методы исследования}

В качестве объектов исследований использовались образцы карамели с начинкой различных торговых марок, реализуемые федеральным ритейлом. Характеристики и производители образцов карамели приведены в табл. 1.

При выполнении исследований использовали:

- квалиметрический метод «дерева свойств» для построения иерархической структуры потребительских показателей качества;

- общепринятые методы исследования показателей качества карамели согласно требованиям ГОСТ 6477-2019 «Карамель. Общие технические условия».
Таблица 1. Производители образцов исследований Table 1. Research Samples Manufacturers
Наименование

карамели

1. «Лимончики»

фруктово-ягодная

2. «Гусиные лапки» с шоколадно-ореховой начинкой

3. «Мечта»

4. «Га-га-га»

5. «КОNTIФрумба» со вкусом яблока

6. Микс с начинкой со вкусами: «Тархун», «Байкал», «Дюшес», «Вишня»

\section{Производитель}

ОАО «Рот Фронт», 115184, Россия, г. Москва, 2-й Новокузнецкий пер., 13/15

АО «Рахат», 050002, Казахстан, г. Алматы, ул. Зенкова, 2а

АО «КОНТИ-РУС», 305000, Россия, г. Курск, ул. Золотая, 13

ООО «Кондитерская фабрика "Богатырь"», 103460, г. Москва, Зеленоград, пр. 4-й Западный, 8, стр. 10
Определение органолептических показателей проводили по ГОСТ 5897.

Вкус, запах, цвет, форму, состояние поверхности, консистенцию и структуру начинки определяли при температуре $(18 \pm 3){ }^{\circ} \mathrm{C}$ в лабораторных условиях.

Наличие влаги определяли по ГОСТ 5900; кислотность - по ГОСТ 5898; содержание начинки (в \%) - весовым методом; определение соответствия массы нетто - по ГОСТ 17527-2014 п. 3.4.11. Анализ маркировки проводили на соответствие требованиям ТР ТС 022/2011 «Пищевая продукция в части ее маркировки». Полученные данные обрабатывались статистическими методами.

\section{Результаты исследования и их обсуждение}

Авторами разработано "дерево свойств» для карамели (см. рисунок). Выделены показатели потребительских свойств, наиболее важные при выборе продукта и не регламентируемые требованиями ГОСТов. Дополнительно были выделены такие показатели, как консистенция и однородность начинки, которые и формируют вкус продукта. Вкус - мультимодальное восприятие, возникающее в результате интеграции множества сенсорных входов; является основным фактором приемлемости для потребителя [4; 13]. Вкус объектов исследования обусловливал их состав, консистенцию оболочки (липкость), консистенцию и однородность начинки, а также ее количество.

Оценка состояния упаковки позволила выявить ее соответствие требованиям нормативных документов. Этикетки изделий выполнены из этикеточной бумаги; образцы 1-5 завернуты вперекрутку; образцы изделия 6 завернуты 


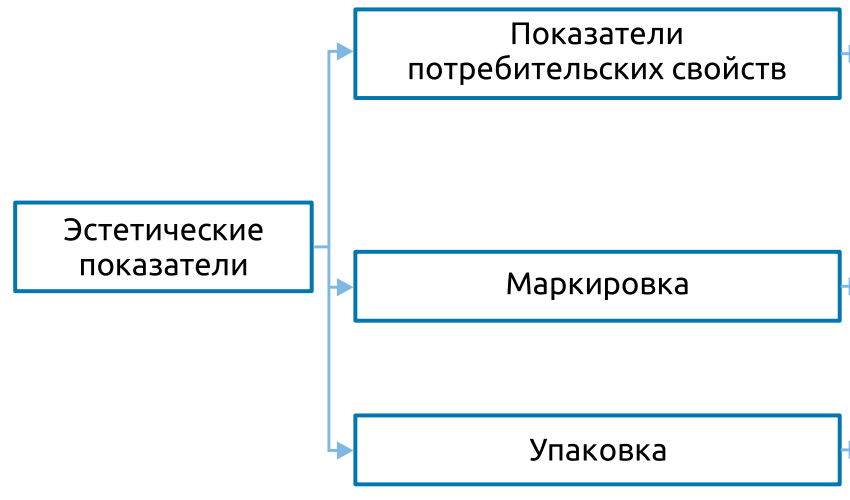

Функциональное значение
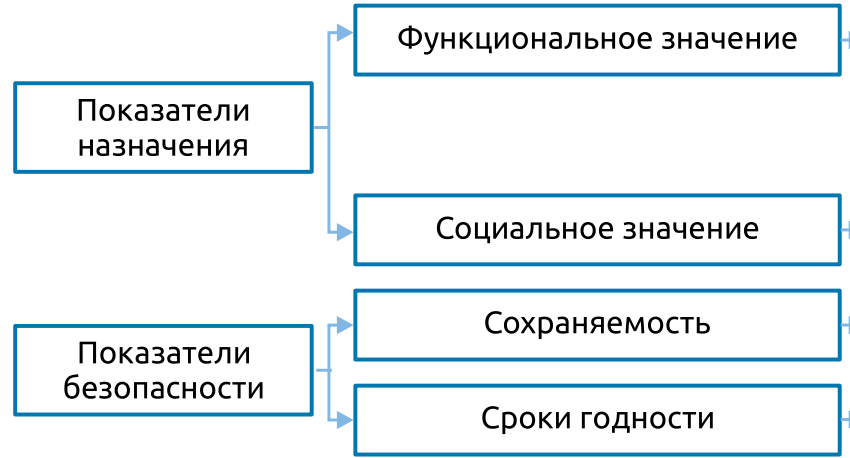

\section{Экологические показатели}

\section{Эргономические} показатели

Экономические
показатели

Соответствие требованиям стандарта ИСО по охране ОС

\section{Удобство применения изделия}

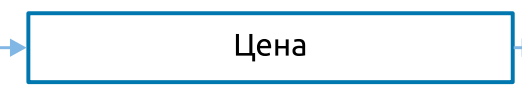

\author{
Форма \\ Цвет \\ Состояние поверхности \\ Запах \\ Вкус \\ Консистенция \\ Однородность начинки
}

Легко читаемый, доступный шрифт

Полнота информации (достаточность)

Соответствие требованиям

Красочность оформления

Целостность, чистота
Внешний вид
Материал упаковки, соответствие массе нетто

Состав (отсутствие консервантов, ароматизаторов, красителей)

Присутствие натуральных компонентов

Пищевая ценность (содержание витаминов, минеральных веществ)

Энергетическая ценность

\section{Доступность}

Популярность

\begin{tabular}{l} 
Соблюдение условий хранения \\
$\begin{array}{l}\text { Сохранение качества на протяжении } \\
\text { срока годности }\end{array}$ \\
\hline
\end{tabular}

Наличие СМК на предприятии изготовителе

Возможность переработки упаковки

Наличие экологических знаков на этикетке

Доступность по цене

\section{"Дерево свойств» для карамели "Properties Tree" for Caramel}

В пленку, запаянную с трех сторон. С эргономической точки зрения наиболее удобна в применении упаковка образцов 1-5.

Анализ маркировки показал следующее: на образцах 4 и 6 не указан вид начинки, что затрудняет выбор потребителя и не соответствует потребительскому критерию «функциональное назначение».

Оценивая экологические показатели, отражающие потребительские критерии охраны окружающей среды, можно отметить, что маркировка всех образцов содержит экологический знак «ресайклинг» (знак переработки упаковки) и знак с призывом «Не сорить!», при этом ни на одном образце информация о наличии СМК на предприятии не указана. В остальном вынесен- ная на этикетку информация характеризуется как полная и доступная, соответствующая требованиям ТР ТС 022/2011.

Анализ состава, пищевой и энергетической ценности карамели, характеризующих потребительский критерий «функциональное назначение», выявил, что состав анализируемых образцов указан на маркировке полностью. В составе всех образцов указаны патока, сахар, кислота лимонная как регулятор кислотности, ароматизаторы натуральные и идентичные натуральным. Синтетические красители содержатся в образцах карамели 5 и 6. Особенностью состава образцов 1, 3 и 5 является наличие пюре яблочного (образец 5), пюре яблочного и подварки лимонной (образцы 1 и 3). В образце 2 содержатся: какао тертое, 
ядро миндаля, заменители масла какао, арахис тертый; в образце 4 - ядра кешью и миндаля, какао тертое, жиры растительные. Энергетическая ценность варьируется от 370-380 (образцы 1, 3, 5 и 6) до 420-430 ккал/100 г (образцы 2 и 4). Только в образце 2 присутствует аскорбиновая кислота. Указание состава, пищевой и энергетической ценности облегчает потребителю выбор с учетом индивидуальных потребностей и предпочтений.

Сроки хранения указаны на всех образцах и составляют от 9 до 15 мес.

Цена изделий за единицу упаковки 250 г составляла от 83 р. (образец 4) до 60-70 р. (образцы 1, 2, 3 и 5), что позволяет выбрать доступный товар потребителям с разным уровнем доходов.

Результаты оценки соответствия массы нетто образцов приведены в табл. 2.

Соответствие массы упаковки имеет значение для потребителя и является важным критерием выбора. Выявлено превышение допустимого отрицательного отклонения массы нетто (3,0 \%) образце 6, у которого отклонение массы составляет $6,7 \%$.

Оценка органолептических показателей выявила следующее.

У образца 1 форма круглая, без деформаций; виден шов; цвет карамели - желтый, равномерный; цвет начинки - коричневый; вкус и запах - кисло-сладкий, вкус начинки - свойственный данному типу карамели, сладкий, ярко выраженный, не имеет посторонних привкусов и запахов; поверхность - сухая, без трещин и вкраплений, гладкая, не липкая, рельефная, нет следов начинки.

Образец 2 имеет овальную форму без деформаций; виден шов; цвет карамели - светло-коричневый, равномерный; цвет начинки - коричневый; вкус карамели - сладкий, свойственный данному типу карамели; вкус начинки - сладкий, ярко выраженный, шоколадный; ярко выражен- ный запах карамели; поверхность - сухая, без трещин и вкраплений, гладкая, не липкая, рельефная, нет следов начинки.

У образца 3 форма круглая, без деформаций; виден шов; цвет карамели - белый, равномерный; цвет начинки - кремовый; вкус и запах карамели - кисло-сладкий, свойственный данному виду карамели; вкус начинки - кисло-сладкий, ярко выраженный; запах карамели - ярко выраженный; поверхность - сухая, без трещин и вкраплений, гладкая, не липкая, нет следов начинки.

У образца 4 имеются явные дефекты: форма - деформированная, овальная; виден шов; поверхность с трещинами, со следами начинки. Цвет, вкус и запах в данном случае соответствуют требованиям ГОСТ. Очевидно, дефекты вызваны неправильным обращением с товаром во время транспортирования и хранения.

Образец 5 имеет круглую форму без деформаций, цвет карамели - зеленый, равномерный; цвет начинки - темно-зеленый; вкус и запах яблочный, кисло-сладкий; вкус начинки - сладкий, ярко выраженный, не имеет посторонних привкусов и запахов; поверхность - сухая, без трещин и вкраплений, гладкая, не липкая, без следов начинки.

Образец 6 имеет треугольную, без деформаций форму; сухую без трещин поверхность; цвет - в зависимости от вкуса карамели («Тархун», «Байкал», «Дюше»с, «Вишня»), равномерный; цвет начинки - белый; вкус и запах - в зависимости от вкуса карамели, кисло-сладкий; вкус начинки - кислый, ярко выраженный, без посторонних привкусов и запахов.

Таким образом, только образец 4 имеет явные дефекты по органолептическим показателям, часто вызванные небрежным обращением с товаром при транспортировании и хранении.

Результаты оценки физико-химических показателей качества приведены в табл. 3.

Таблица 2. Результаты оценки массы нетто образцов исследования в сравнении с заявленной* Table 2. Evaluation Results of the Net Weight of the Study Samples in Comparison with the Declared One

\begin{tabular}{|l|c|c|}
\multicolumn{1}{|c|}{ Наименование карамели } & \multicolumn{2}{|c|}{ Масса нетто карамели, г } \\
\cline { 2 - 3 } & Заявленная & Фактическая \\
\hline 1. «Лимончики» фруктово-ягодная & 250 & 259,5 \\
\hline 2. «Гусиные лапки» с шоколадно-ореховой начинкой & 250 & 253,0 \\
\hline 3. «Мечта» & 250 & 253,0 \\
\hline 4. «Га-га-га» & 245 & 254,0 \\
\hline 5. «КОКТІФрумба» со вкусом яблока & 248 & 246,0 \\
\hline 6. Микс с начинкой со вкусами: «Тархун», «Байкал», «Дюшес», «Вишня» & 120 & 112,0 \\
\hline
\end{tabular}

Примечание. *Указано на упаковке. 
Таблица 3. Физико-химические показатели качества образцов исследования Table 3. Physical and Chemical Indicators of the Study Samples Quality

\begin{tabular}{|c|c|c|c|c|c|c|c|}
\hline \multirow{2}{*}{ Показатель } & \multirow{2}{*}{$\begin{array}{c}\text { ГОСТ } \\
6477-2019\end{array}$} & \multicolumn{6}{|c|}{ Факт } \\
\hline & & 1 & 2 & 3 & 4 & 5 & 6 \\
\hline Кислотность, град & $7,1-16,0$ & $10,0+0,1$ & $2,4+0,1$ & $9,0+0,1$ & $3,0+0,1$ & $8,4+0,1$ & $12,0+0,1$ \\
\hline $\begin{array}{l}\text { Влажность карамельной } \\
\text { массы, \% }\end{array}$ & Не более 3 & $1,1+0,2$ & $1,04+0,20$ & $1,08+0,20$ & $1,0+0,20$ & $1,04+0,20$ & $1,09+0,20$ \\
\hline Количество, шт./кг & & 172 & 147 & 227 & 142 & 185 & 240 \\
\hline $\begin{array}{l}\text { Массовая доля начинки, \%, } \\
\text { не менее }\end{array}$ & $\begin{array}{c}\text { № } 1,5,6-28 \text {; } \\
\text { № } 2,4-31 \text {; } \\
\text { № } 3-25\end{array}$ & $24,5+0,5$ & $36,0+0,5$ & $30,0+0,5$ & $31,9+0,5$ & $13,3+0,5$ & $17,7+0,5$ \\
\hline
\end{tabular}

Полученные данные свидетельствуют о соответствии показателей кислотности и влажности исследуемых образцов требованиям нормативного документа. Выявлены несоответствия массовой доли начинки в образцах карамели 1, 5 и 6.

Содержание начинки занижено в среднем: в образце 1 - на 3,5 \%; в образце 5 - на 15 \%; в образце 6-на $10 \%$.

\section{Выводы}

Применение инструмента управления качеством, В частности иерархической структуры "дерева свойств», позволило выявить потребительские критерии, наиболее значимые и объективно отражающие выбор потребителя. Из показателей социального назначения ключевым для потребителя является доступная цена, при этом изделие должно обладать соответствую- щими сенсорными характеристиками и не иметь в составе синтетических ароматизаторов и красителей. Эстетические показатели отражают доступную и достоверную информацию о продукте, вид упаковочного материала и красочность оформления, а также влияние утилизации упаковки на окружающую среду.

В процессе исследования установлено соответствие заявленному критерию всех образцов, кроме образца 4, по органолептическим показателям качества.

По физико-химическим показателям качества выявлено несоответствие образцов 1, 5 и 6 по содержанию начинки.

Полученные результаты могут быть полезны практикующим работникам торговли при формировании ассортимента продукции торговой организации.

\section{Библиографический список}

1. Резниченко И.Ю., Фролова Н.А., Кучебо В.В., Туров С.В. Использование сиропов в рецептуре сахаристых кондитерских изделий повышенной пищевой ценности // Техника и технология пищевых производств. 2019. Т. 49, № 1. C. 62-69. DOI: 10.21603/20749414-2019-1-62-69.

2. Степакова Н.Н., Резниченко И.Ю., Киселева Т.Ф., Шкрабтак Н.В., Фролова Н.А., Праскова Ю.А. Растительное сырье дальневосточного региона как источник биологически активных веществ // Пищевая промышленность. 2020. № 3. С. 16-21. DOI: 10.24411/0235-2486-2020-10025.

3. Резниченко И.Ю., Галиева А.И. Разработка и оценка каче ства нового сахаристого кондитерского изделия // Международный научно-исследовательский журнал. 2013. № 8-2 (15) C. 59-60.

4. Paravisiniab, L.; Morettonb, C.; Gouttefangeasb, C.; Nigayb, H.; Dacremonta, C.; Guichard, E. Caramel Flavour Perception: Impact of the Non-Volatile Compounds on Sensory Properties and In-Vitro Aroma Release. Food Research International. 2017. Vol. 100, part 1. Pp. 209-215. DOI: 10.1016/j.foodres.2017.07.003.

\section{Bibliography}

1. Reznichenko, I.Yu.; Frolova, N.A.; Kuchebo, V.V.; Turov, S.V. Ispol'zovanie Siropov v Recepture Saharistyh Konditerskih Izdelij Povyshennoj Pishchevoj Cennosti [Syrups Use in the Sugary Confectionery Products Formulation of Increased Nutritional Value]. Tekhnika i Tekhnologiya Pishchevyh Proizvodstv. 2019. T. 49, No. 1. Pp. 62-69. DOI: 10.21603/2074- 9414-2019-1-62-69.

2. Stepakova, N.N.; Reznichenko, I.Yu.; Kiseleva, T.F.; Shkrabtak, N.V.; Frolova, N.A.; Praskova, Yu.A. Rastitel'noe Syr'e Dal'nevostochnogo Regiona kak Istochnik Biologicheski Aktivnyh Veshchestv [Plant Raw Materials of the far Eastern Region as the Source of Biologically Active Substance]. Pishchevaya Promyshlennost'. 2020. No. 3. Pp. 16-21. DOI: 10.24411/0235-2486-2020-10025.

3. Reznichenko, I.Yu.; Galieva, A.I. Razrabotka i Ocenka Kachestva Novogo Saharistogo Konditerskogo Izdeliya [Development and Quality Assessment of a New Sugar Confectionery Product]. Mezhdunarodnyj Nauchno-Issledovatel'skij Zhurnal. 2013. No. 8-2 (15). Pp. 59-60.

4. Paravisiniab, L.; Morettonb, C.; Gouttefangeasb, C.; Nigayb, H.; Dacremonta, C.; Guichard, E. Caramel Flavour Perception: Impact of the Non-Volatile Compounds on Sensory Properties and In-Vitro Aroma Release. Food Research International. 2017. Vol. 100, part 1. Pp. 209-215. DOI: 10.1016/j.foodres.2017.07.003. 
5. Заворохина Н.В. Разработка рецептур и технологии низкокало рийной кондитерской продукции // Товароведно-технологические аспекты повышения качества и конкурентоспособности продукции: сб. материалов Междунар. науч.-практ. конф. (Новосибирск, 31 августа 2018 г.). Новосибирск: Изд-во Сибирского университета потребительской кооперации, 2018. С. 114-119. ISBN 978-5-334-00182-4.

6. Сандракова И.В., Резниченко И.Ю. Исследование потребителей продуктов здорового питания // Практический маркетинг. 2019. № 12 (274). С. 22-27.

7. Школьникова М.Н., Чугунова О.В., Лазарев В.А., Карх Д.А. Потребительские предпочтения населения как исходная информация при повышении пищевой ценности кондитерских изделий // Пищевая промышленность. 2019. № 6. C. 45-49. DOI: 10.24411/0235-2486-2019-10087.

8. Гурьянов Ю.Г., Лобач Е.Ю., Резниченко И.Ю. Оценка потреби тельских предпочтений к новым продуктам функционального назначения // Ползуновский вестник. 2012. № 2-2. С. 187-190.

9. Фролова Н.А., Резниченко И.Ю., Иванкина Н.Ф. Анализ потребительских предпочтений жителей г. Благовещенска Амурской области в отношении карамели, обогащенной биологически активными веществами из растительного и животного сырья // Техника и технология пищевых производств. 2012. № 2 (25). C. 168-172.

10. Frolova, N.; Pomozova, V.; Kiseleva, T.; Pekov, D.; Shkrabtak, N.; Reznichenko, I. The Development Trend of the Confectionery Market of the Russian Federation. Proceedings of the 2nd International Conference on Education Science and Social Development (ESSD 2019). Published by Atlantis Press, 2019. Pp. 385-388. ISBN 978-94 6252-758-4. ISSN 2352-5398. DOI: 10.2991/essd-19.2019.85.

11. Mayhewa, E.J.; Schmidt, S.J.; Schlich, P.; Lee, S.Y. Correlation of consumer perception of stickiness and contributing texture attributes to trained panelist temporal evaluations in a caramel system. Food Quality and Preference. 2018. Vol. 65. Pp. 72-80. DOI: 10.1016/j.foodqual.2017.11.009.

12. Зайцева Н.С., Рубан Н.Ю., Резниченко И.Ю. Оценка уровня ка чества шоколада с применением дескрипторно-профильного метода // АПК России. 2020. Т. 27, № 4. С. 706-713.

13. Frolova, N.; Praskova, Y.; Reznichenko, I. Regional Aspects of the International Development of the Confectionery Industry for the Border Areas of the Far Eastern Region. Proceedings of the International Conference on Sustainable Development of Cross-Border Regions: Economic, Social and Security Challenges (ICSDCBR 2019) (Barnaul, 2019, April 18-19). Published by Atlantis Press, 2019. Vol. 364. Pp. 89-92. ISBN 978-94-6252-831-4. ISSN 2352- 5398. DOI: 10.2991/icsdcbr-19.2019.19.
5. Zavorohina, N.V. Razrabotka Receptur i Tekhnologii Nizkokalorijnoj Konditerskoj Produkcii [Recipes and Technologies Development of Low-Calorie Confectionery Products]. Tovarovedno-Tekhnologicheskie Aspekty Povysheniya Kachestva i Konkurentosposobnosti Produkcii: Sb. Materialov Mezhdunar. Nauch.-Prakt. Konf. (Novosibirsk, 31 Avgusta 2018 g.). Novosibirsk: Izd-vo Sibirskogo Universiteta Potrebitel'skoj Kooperacii, 2018. Pp. 114-119. ISBN 978-5-334-00182-4.

6. Sandrakova, I.V.; Reznichenko, I.Yu. Issledovanie Potrebitelej Produktov Zdorovogo Pitaniya [Consumers Research of Healthy Food Products]. Prakticheskij Marketing. 2019. No. 12 (274). Pp. $22-27$.

7. Shkolnikova, M.N.; Chugunova, O.V.; Lazarev, V.A.; Karh, D.A. Potrebitel'skie Predpochteniya Naseleniya kak Iskhodnaya Informaciya pri Povyshenii Pishchevoj Cennosti Konditerskih Izdelij [Population Consumer Preferences as Initial Information when Increasing the Nutritional Value of the Confectionery Products]. Pishchevaya Promyshlennost'. 2019. No. 6. Pp. 45-49. DOI: 10.24411/0235-24862019-10087.

8. Gurjyanov, Yu.G.; Lobach, E.Yu.; Reznichenko, I.Yu. Ocenka Potrebitel'skih Predpochtenij k Novym Produktam Funkcional'nogo Naznacheniya [Consumer Preferences Evaluation for New Functional Products]. Polzunovskij Vestnik. 2012. No. 2-2. Pp. 187-190.

9. Frolova, N.A.; Reznichenko, I.YU.; Ivankina, N.F. Analiz Potrebitel'skih Predpochtenij ZHitelej g. Blagoveshchenska Amurskoj Oblasti v Otnoshenii Karameli, Obogashchennoj Biologicheski Aktivnymi Veshchestvami iz Rastitel'nogo I ZHivotnogo Syr'ya [Consumer Preferences Analysis of Residents of Blagoveshchensk of the Amur Region in Relation to Caramel Enriched with Biologically Active Substances from Vegetable and Animal Raw Materials]. Tekhnika i Tekhnologiya Pishchevyh Proizvodstv. 2012. No. 2 (25). Pp. 168-172.

10. Frolova, N.; Pomozova, V.; Kiseleva, T.; Pekov, D.; Shkrabtak, N.; Reznichenko, I. The Development Trend of the Confectionery Market of the Russian Federation. Proceedings of the 2nd International Conference on Education Science and Social Development (ESSD 2019). Published by Atlantis Press, 2019. Pp. 385-388. ISBN 978-946252-758-4. ISSN 2352-5398. DOI: 10.2991/essd-19.2019.85.

11. Mayhewa, E.J.; Schmidt, S.J.; Schlich, P.; Lee, S.Y. Correlation of Consumer Perception of Stickiness and Contributing Texture Attributes to Trained Panelist Temporal Evaluations in a Caramel System. Food Quality and Preference. 2018. Vol. 65. Pp. 72-80. DOI: 10.1016/j.foodqual.2017.11.009.

12. Zajtseva, N.S.; Ruban, N.Yu.; Reznichenko, I.Yu. Ocenka Urovnya Kachestva Shokolada s Primeneniem Deskriptorno-Profil'nogo Metoda [Chocolate Quality Level Evaluation Using the Descriptor-Profile Method]. APK Rossii. 2020. T. 27, No. 4. Pp. 706-713.

13. Frolova, N.; Praskova, Y.; Reznichenko, I. Regional Aspects of the International Development of the Confectionery Industry for the Border Areas of the Far Eastern Region. Proceedings of the International Conference on Sustainable Development of Cross-Border Regions: Economic, Social and Security Challenges (ICSDCBR 2019), (Barnaul, 2019, April 18-19). Published by Atlantis Press, 2019. Vol. 364. Pp. 89-92. ISBN 978-94-6252-831-4. ISSN 2352- 5398. DOI: 10.2991/icsdcbr-19.2019.19. 


\section{Информация 06 авторах / Information about Authors}

Резниченко

Ирина Юрьевна

Reznichenko

Irina Yurievna

Тел./Phone: +7 (3842) 39-68-54

E-mail: irina.reznichenko@gmail.com

\section{Фролова \\ Нина Анатольевна \\ Frolova, \\ Nina Anatolyevna \\ тел./Phone: +7 (4162) 23-46-56 \\ E-mail:ninelfr@mail.ru}

\section{Жарская \\ Екатерина Евгеньевна}

Zharskaya,

Ekaterina Evgenievna

тел./Phone: +7 (3842) 39-68-54

E-mail:

impudentksksks190515@gmail.com

\section{Ковальчук \\ Яна Сергеевна}

Kovalchuk,

Yana Sergeevna

тел./Phone: +7 (3842) 39-68-54

E-mail:yana.k.prk@gmail.com

\section{Соловьева \\ Маргарита Артуровна}

Solov'eva,

Margarita Arturovna

тел./Phone: +7 (3842) 39-68-54

E-mail: r.soloviova52@gmail.com
Доктор технических наук, профессор, заведующий кафедрой управления качеством Кемеровский государственный университет

650000, Российская Федерация, Кемерово, ул. Красная, 6

Doctor of Technical Science, Professor, Head of the Quality Management Department Kemerovo State University

650000, Russian Federation, Kemerovo, Krasnaya St., 6

ORCID: https://orcid.org/0000-0002-7486-4704

Кандидат технических наук, дочент кафедры безопасности жизнедеятельности Амурский государственный университет

675027, Российская Федерация, г. Благовещенск, Игнатьевское шоссе, 21

Candidate of Technical Science, Associate Professor of the Life Safety Department Amur State University

675027, Russian Federation, Blagoveshchensk, Ignatievskoe Ave., 21

ORCID: https://orcid.org/0000-0003-0141-1998

Студент кафедры управления качеством Кемеровский государственный университет 650000, Российская Федерация, Кемерово, ул. Красная, 6

Student of the Quality Management Department

Kemerovo State University 650000, Russian Federation, Kemerovo, Krasnaya St., 6

ORCID: https://orcid.org/0000-0001-9782-2921

Студент кафедры управления качеством Кемеровский государственный университет 650000, Российская Федерация, Кемерово, ул. Красная, 6

Student of the Quality Management Department Kemerovo State University 650000, Russian Federation, Kemerovo, Krasnaya St., 6

ORCID: https://orcid.org/0000-0002-3757-5241

Студент кафедры управления качеством Кемеровский государственный университет 650000, Российская Федерачия, Кемерово, ул. Красная, 6

Student of the Quality Management Department Kemerovo State University 650000, Russian Federation, Kemerovo, Krasnaya St., 6 ORCID: https://orcid.org/0000-0002-5696-287X 